\title{
Performance Analysis of a New Thermal Stratification Device for Hot Water Storage Tank Heated at the Bottom
}

\author{
Fan, Jianhua; Ptacek, Vaclav; Furbo, Simon; Dragsted, Janne; Sun, Pengjie
}

Published in:

Conference Proceedings - Solar World Congress 2015

Link to article, DOI:

10.18086/swc.2015.02.14

Publication date:

2016

Document Version

Publisher's PDF, also known as Version of record

Link back to DTU Orbit

Citation $(A P A)$ :

Fan, J., Ptacek, V., Furbo, S., Dragsted, J., \& Sun, P. (2016). Performance Analysis of a New Thermal Stratification Device for Hot Water Storage Tank Heated at the Bottom. In Conference Proceedings - Solar World Congress 2015 International Solar Energy Society. https://doi.org/10.18086/swc.2015.02.14

\section{General rights}

Copyright and moral rights for the publications made accessible in the public portal are retained by the authors and/or other copyright owners and it is a condition of accessing publications that users recognise and abide by the legal requirements associated with these rights.

- Users may download and print one copy of any publication from the public portal for the purpose of private study or research.

- You may not further distribute the material or use it for any profit-making activity or commercial gain

- You may freely distribute the URL identifying the publication in the public portal 


\title{
PERFORMANCE ANALYSIS OF A NEW THERMAL STRATIFICATION DEVICE FOR HOT WATER STORAGE TANK HEATED AT THE BOTTOM
}

\author{
Jianhua Fan ${ }^{1}$, Vaclav Ptacek ${ }^{1}$, Simon Furbo ${ }^{1}$, Janne Dragsted ${ }^{1}$ and Pengjie Sun ${ }^{2}$ \\ ${ }^{1}$ Department of Civil Engineering, Technical University of Denmark, Denmark \\ ${ }^{2}$ Beijing Computing Center, Beijing, China
}

\begin{abstract}
Thermal stratification in heat storage tank has a major influence on the thermal performance of the heating system. For heat storage tank heated from the bottom, the whole tank is heated in order to provide hot water for the consumer. A new stratification device has been developed to place the heated water at the top of the tank, therefore allowing the energy usage to be reduced since the whole tank does not need to be heated to provide hot water. The aim of the paper is to investigate the performance of the newly developed thermal stratification device by means of experiments and computational fluid dynamics (CFD) simulations. Experiments have been carried out to measure water temperatures at different levels of the tank during charging by a vertical heating element integrated in the stratification device. A simplified CFD model of the cylindrical heat storage tank with the stratification device and a heating element at the bottom of the tank is created in Ansys Fluent 15.0. Transient fluid flow and heat transfer in the tank during charging are calculated. The CFD calculated water temperatures are compared to the measured temperatures. A parametric study has been carried out to investigate how thermal stratification in the tank is influenced by the design of the stratifier such as pipe thickness, material type, diameter of the pipe, by dimensions of the tank and by power of the heating element, etc.
\end{abstract}

The investigations elucidate how well a hot water tank heated at the bottom with a vertical heating element can be stratified by using the new stratifier design. Based on the CFD calculations, design of the stratification device is optimized.

Keywords: Heat storage tank, thermal stratification, stratification device, Computational fluid dynamics (CFD), Experiments

\section{Introduction}

Thermal stratification in heat storage tanks has a major influence on the thermal performance of solar heating systems. A high degree of thermal stratification in the storage tank increases the thermal performance of a solar heating system because the return temperature to the solar collector is lowered (Furbo 1984, van Koppen C 1979, Furbo 1987). A lower inlet temperature to the solar collector will increase the efficiency and operating hours of the solar collector. Further, the temperature at the top of the storage will be closer to the desired load temperature. Therefore the auxiliary energy consumption will be decreased which increases the solar fraction (Hollands 1989, Furbo 2006). Thermal stratification and natural convection flow in a vertical cylindrical hot water tank during standby periods were investigated in previous investigations (Andersen 2007, Fan 2012a, 2012b). Transient, three-dimensional CFD models of hot water storage tanks were developed and validated against thermal measurements. The results show that the CFD calculation predicts satisfactorily the water temperatures in the tank during cooling of the tank. The natural convection flow along the tank sides is strongly influenced by the thermal stratification in the tank.

A tank heated from the bottom could be used as heat storage in a solar heating system, or as heat storage for PV heating. Compared to conventional tank, it is more difficult to ensure high degree of thermal stratification in the tank heated from the bottom as natural convection in the tank created by the heating element will mix water in the tank therefore destroying thermal stratification in the tank. Typically the whole tank is heated in order to provide hot water for the consumer. A new stratification device has been developed to place the 
heated water at the top of the tank, therefore allowing the energy usage to be reduced since the whole tank does not need to be heated to provide hot water for the consumer.

The aim of the paper is to analyze performance of the newly developed thermal stratification device by means of experiments and computational fluid dynamics (CFD) simulations.

\section{The investigation methods}

Experiments have been carried out to investigate thermal performance of the newly developed stratification device. Fig. 1 shows test setup a cylindrical heat storage tank of 110 liters installed with a stratification device. The tank is made of $2 \mathrm{~mm}$ steel. The stratification device is mounted at the bottom of the cylindrical tank, see Fig. 1A. The stratification device consists of two parts: A steel pipe with a diameter of $115 \mathrm{~mm}$ at the bottom and a plastic pipe with a diameter of $20 \mathrm{~mm}$ at the top, see Fig. 1B. Inside the steel pipe of the stratification device there is a vertical electrical heating element of $2.91 \mathrm{~kW}$ installed. When heated by the heating element, water in the stratification device rises up and enters in the tank though an opening at the top of the plastic pipe, while there are gaps at the bottom of the stratification device, allowing water from the tank to enter into the inlet stratification device. This forms a circulation of water flow driven by natural convection. Photo of the tank is shown in Fig. 1C. Experiments have been carried out to measure water temperatures at different levels of the tank during charging at different operation conditions.

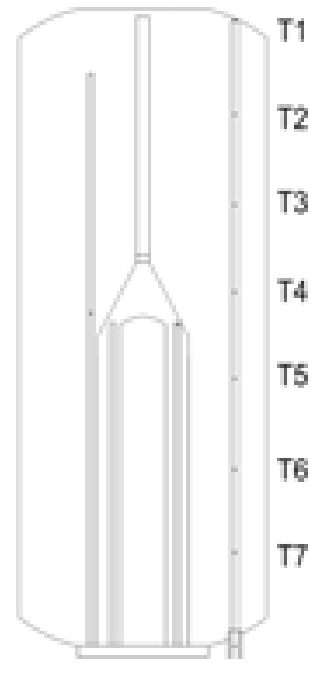

(A) design of the tank

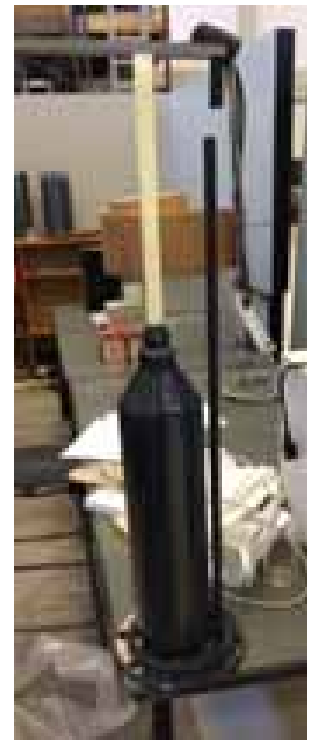

(B) photo of the stratification device

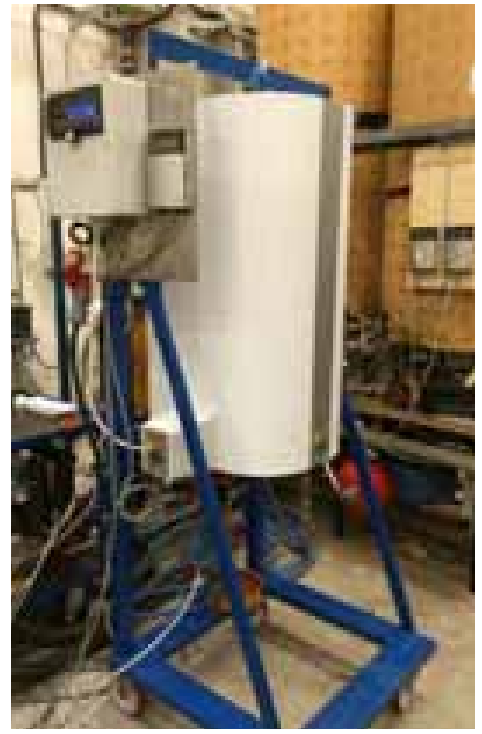

(C) photo of the tank

Fig. 1: Experimental setup of a heat storage tank with a stratification device

A simplified CFD model of the cylindrical heat storage tank charged with a heating element at the bottom of the tank is created in Ansys Fluent 15.0, see Fig. 2. The tank has a diameter of $394 \mathrm{~mm}$ and a height of 841 $\mathrm{mm}$, resulting in a volume of 110 liters. The stratification device is placed in the middle of the tank, stretching from the bottom to the top of the tank. The bottom part of the device is a steel pipe with a diameter of $115 \mathrm{~mm}$ and a thickness of $4.3 \mathrm{~mm}$, while the upper part of the device is a plastic pipe with a diameter of $20 \mathrm{~mm}$ and a thickness of $2.3 \mathrm{~mm}$, see Fig. 2. The parabolic top end and bottom end of the tank are made flat in order to facilitate good meshing. The water volume above the opening of the plastic pipe and the dead volume at the bottom of the tank were kept the same as the tank in experiment, therefore influences on thermal stratification by the simplification is minimized. The 3D tank model includes the steel tank wall as a solid region and the hot water volume of the tank as a fluid region while the insulation materials are not directly modelled. The effect of the insulation materials is considered by the heat loss coefficients measured by the experiment. The heat loss coefficient of the tank is divided into three parts: heat loss coefficient of the top surface, of the side surface and of the bottom surface. The heat loss coefficients measured by the experiments are used as input to the model. The following equations are used to calculate temperature 
dependent heat loss coefficients of the tank:
$K_{\text {top }}=0.24+0.00015 * \mathrm{t}$
$[\mathrm{W} / \mathrm{K}]$
(eq. 1)
$K_{\text {side }}=1.75+0.00148 * \mathrm{t}$
$K_{\text {bottom }}=0.41+0.00034 * \mathrm{t}$
$K_{\text {total }}=2.4+0.00198 * \mathrm{t}$

where $\mathrm{t}$ is the water temperature in the tank, $\left[{ }^{\circ} \mathrm{C}\right]$.

Mean average ambient air temperature during the experiment is used as the free stream temperature of the tank surfaces. The tank wall material, steel, has a thermal conductivity of $60 \mathrm{~W} / \mathrm{K} / \mathrm{m}$ and a density of 7850 $\mathrm{kg} / \mathrm{m}^{3}$.
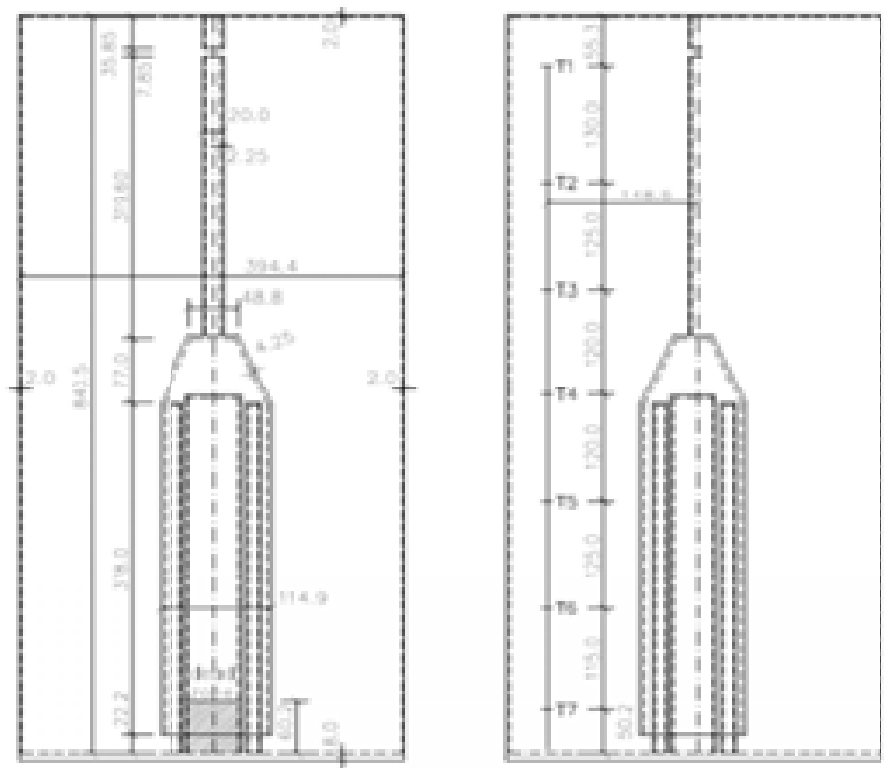

Fig. 2: Simplified CFD model of the tank with a stratification device

The mesh on the vertical cut-plane of the tank is shown in Fig. 3A. In order to better resolve the heat transfer and fluid flow in the region adjacent to the tank wall, a boundary layer mesh is applied so that there is a fine and dense mesh in the area close to the wall, see Fig. 3B and 3C.

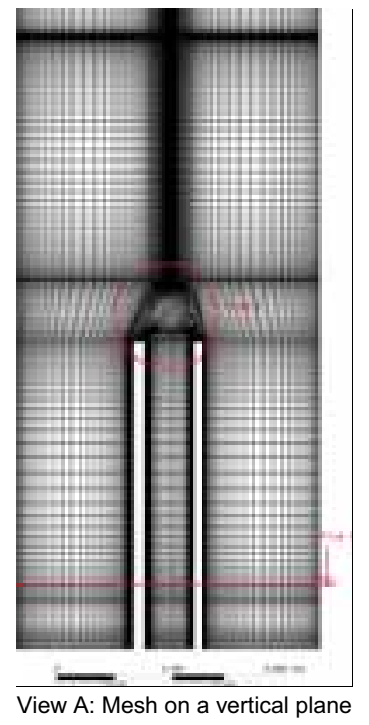

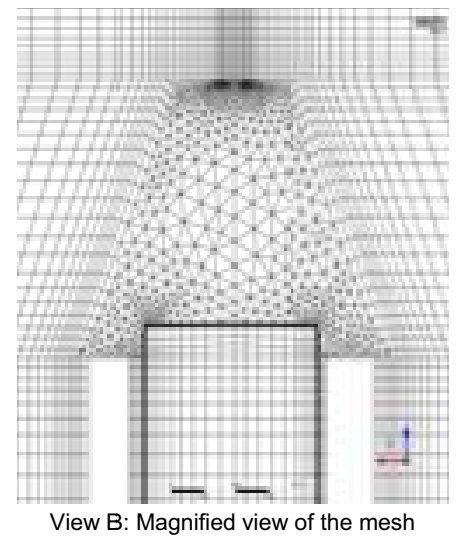

Fig. 3: Mesh of the CFD model of the tank

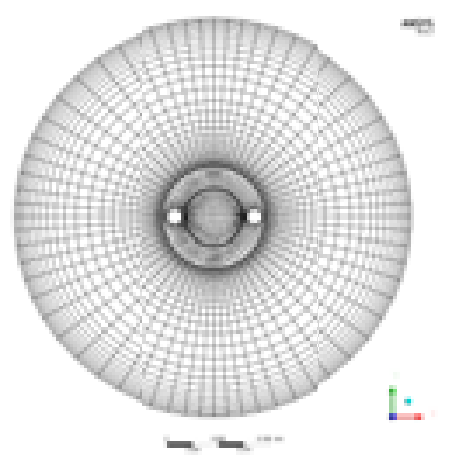

View C: Mesh at a horizontal plan 
Calculation of Rayleigh number shows that the flow in the tank is turbulent, therefore the k- $\varepsilon$ turbulent model is used in the calculation. Transient CFD calculations are performed with Boussinesq approximation. The PRESTO and second order upwind method are used for the discretization of the pressure and the momentum/energy equations respectively. The SIMPLE algorithm is used to treat the pressure-velocity coupling. The transient simulations start with a cold tank with temperature close to the ambient air temperature. A zero velocity field is assumed at the start of all simulations. The calculation is considered convergent if the scaled residual for the continuity equation, the momentum equations and the energy equation are less than $10^{-3}, 10^{-3}$ and $10^{-6}$ respectively. The simulation runs with a time step of $1 \mathrm{~s}$ and a duration of $1 \mathrm{~h}$. One simulation takes approximately 24 hours for a quad-core processor computer with 4 X 3 $\mathrm{GHz}$ CPU frequency and 8G memory.

\section{Validation of the CFD model}

Transient fluid flow and heat transfer in the tank during charging are calculated. The CFD calculated water temperatures are compared to the measured temperatures. Fig. 4 shows measured and calculated temperatures in the tank at 7 different levels of the tank after 1 hour of charging from a cold tank. Locations of the temperature sensors are illustrated in Fig. 1A. Measured temperatures are shown with a title ' $\mathrm{t}_{\mathrm{e}}{ }^{*}$ ' while CFD calculated temperatures are shown with a title ' $t_{c} *$ '. The last number in the title ' $*$ ' indicates the location of temperature sensor. The charging power is $2.91 \mathrm{~kW}$. At the start of the charging, the measured temperature at the top of the tank was $5 \mathrm{~K}$ higher than the temperature used in the CFD model. This difference in temperatures will influence the difference between measured and calculated temperature as water at the top of the tank will slowly flow towards the bottom of the tank during charging.

The difference between the measured and the calculated temperatures is within the range of $0-4 \mathrm{~K}$ at the end of the charging. It can be seen that there is a good agreement between the measured and the CFD calculated temperatures through the whole tank, therefore the CFD model is considered reliable. The validated CFD will then be used to investigate how thermal stratification in the tank is influenced by different designs of the stratification device.

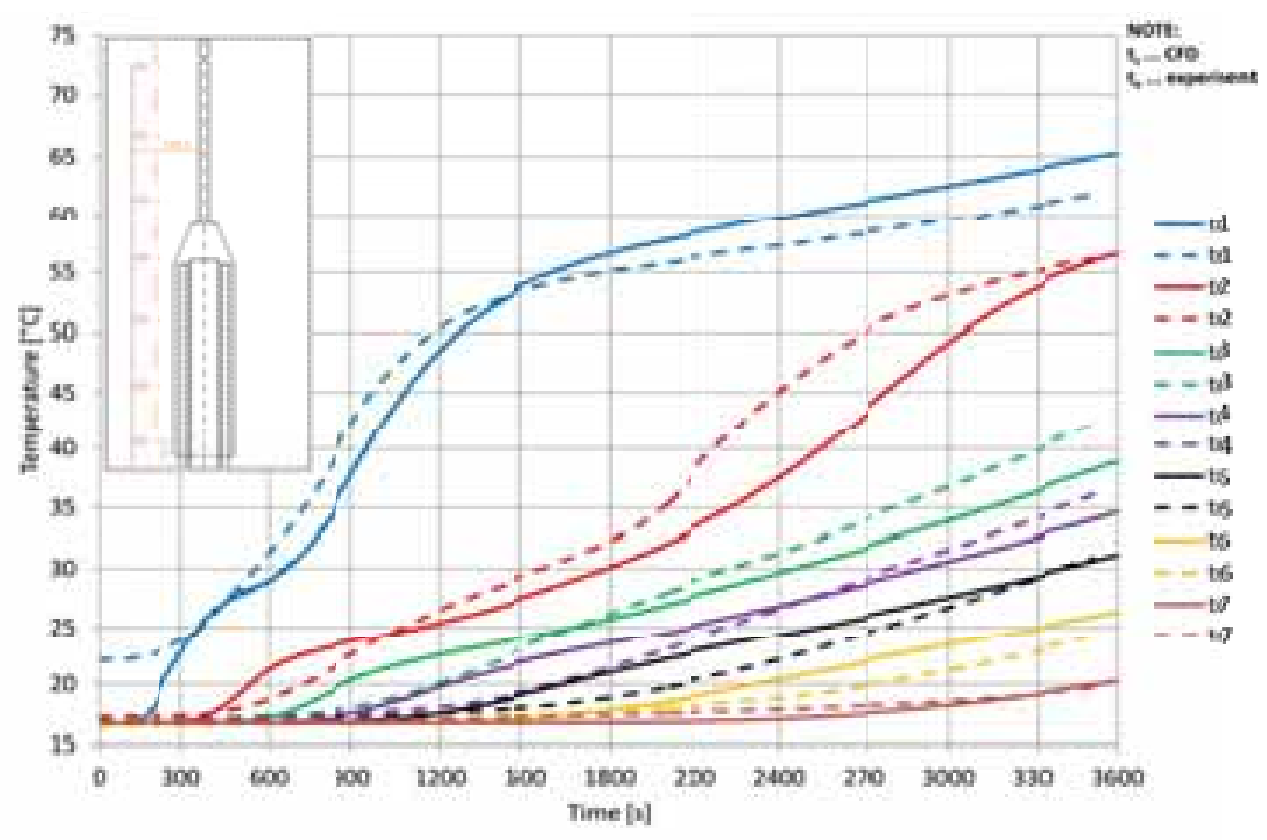

Figur 4. Measured and calculated temperatures in the tank during a $1 \mathrm{~h}$ charge $\left(t_{c} . .\right.$, CFD; $t_{e} \ldots$, experiment). 


\section{Parametric analysis}

The validated CFD model is used to calculate water temperatures in the 1101 Metro tank after 1 hour of charging. At the start of the charging, the tank has a uniform tank temperature of $16.5^{\circ} \mathrm{C}$. Calculations are carried out to investigate the influence of the design of the stratification device on thermal stratification in the tank. The investigations focuses on diameter and wall thickness of the PEX pipe, opening area of the PEX pipe, diameter of the hole separating the plastic pipe and the steel pipe as well as dimeter, wall thickness for the steel pipe around the heating element. Also calculations with a PP pipe around the heating element were carried out. The charging power is $2.91 \mathrm{~kW}$ in the calculations.

\subsection{Diameter and wall thickness of the PEX pipe}

Fig. 5 shows calculated temperatures in the tank during a 1 hour charge with different diameters of the PEX pipe. The PEX pipe in the experiments has an outer diameter of $20 \mathrm{~mm}$ and an inner diameter of $15.5 \mathrm{~mm}$, therefore $20 / 15.5 \mathrm{~mm}$ is used as a reference. In Fig. 5, 'tb*', ' $t * 16 \mathrm{~mm}$ ' and ' $t * 25 \mathrm{~mm}$ ' represent the reference pipe of $20 / 15.5 \mathrm{~mm}$, a pipe of $16 / 12 \mathrm{~mm}$ and a pipe of $25 / 20.4 \mathrm{~mm}$ respectively. The last number in the title ' $*$ ' indicates the location of temperature sensor. It can be seen that the diameter of the PEX pipe has almost no influence on water temperatures in the tank, therefore it can be concluded that thermal stratification is not influenced by diameter of the PEX pipe if pipe diameter lies within the range from 16-25 $\mathrm{mm}$. It indicates that the investigated pipe diameters are sufficient large so that they will not create significant friction loss for the natural convection flow in the pipe during charging.

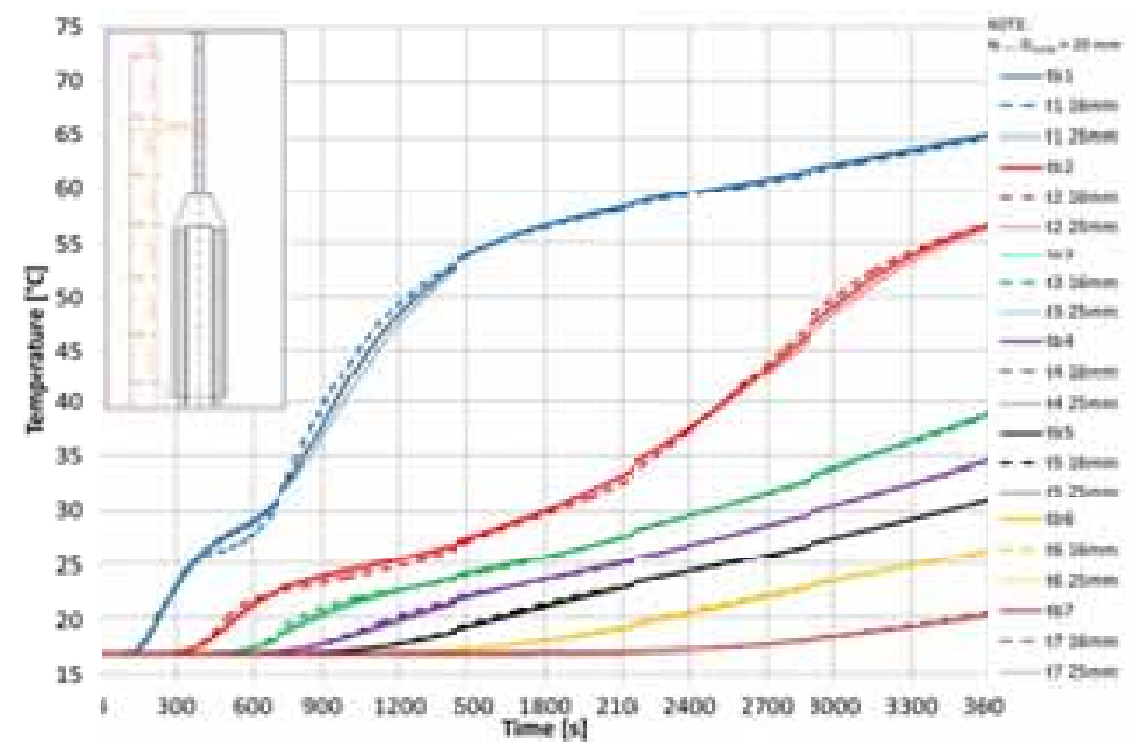

Figur 5. Calculated tank temperatures during a 1 (h) charge for different PEX pipe diameters.

Fig. 6 shows calculated water temperatures during a 1 hour charge with different wall thicknesses of the PEX pipe. The PEX pipe in the experiments has a wall thickness of $2.25 \mathrm{~mm}$, which is shown as reference in Fig. 6 . The text ' $\mathrm{bb}^{*}$ ', ' $\mathrm{t} * 1 \mathrm{~mm}$ ' and ' $\mathrm{t} * 3 \mathrm{~mm}$ ' represent respectively wall thickness of $2.25 \mathrm{~mm}, 1 \mathrm{~mm}$ and $3 \mathrm{~mm}$. The last number in the title '*' indicates the location of temperature sensor. It shows that the wall thickness has insignificant influence on water temperatures in the tank. The tank with a PEX pipe wall thickness of $2.25 \mathrm{~mm}$ has almost the same temperature as the tank with a pipe wall thickness of $3 \mathrm{~mm}$ while with a wall thickness of $1 \mathrm{~mm}$, there is a larger temperature difference. The largest temperature difference between the three tanks is smaller than $1 \mathrm{~K}$. It means that further increase of wall thickness will not make any influence on thermal stratification in the tank while the thermal stratification tends to get worse with a decrease of wall thickness to be below $1 \mathrm{~mm}$. This could be explained by a larger heat transfer from the hot water in the pipe to water in the tank through the pipe wall. 


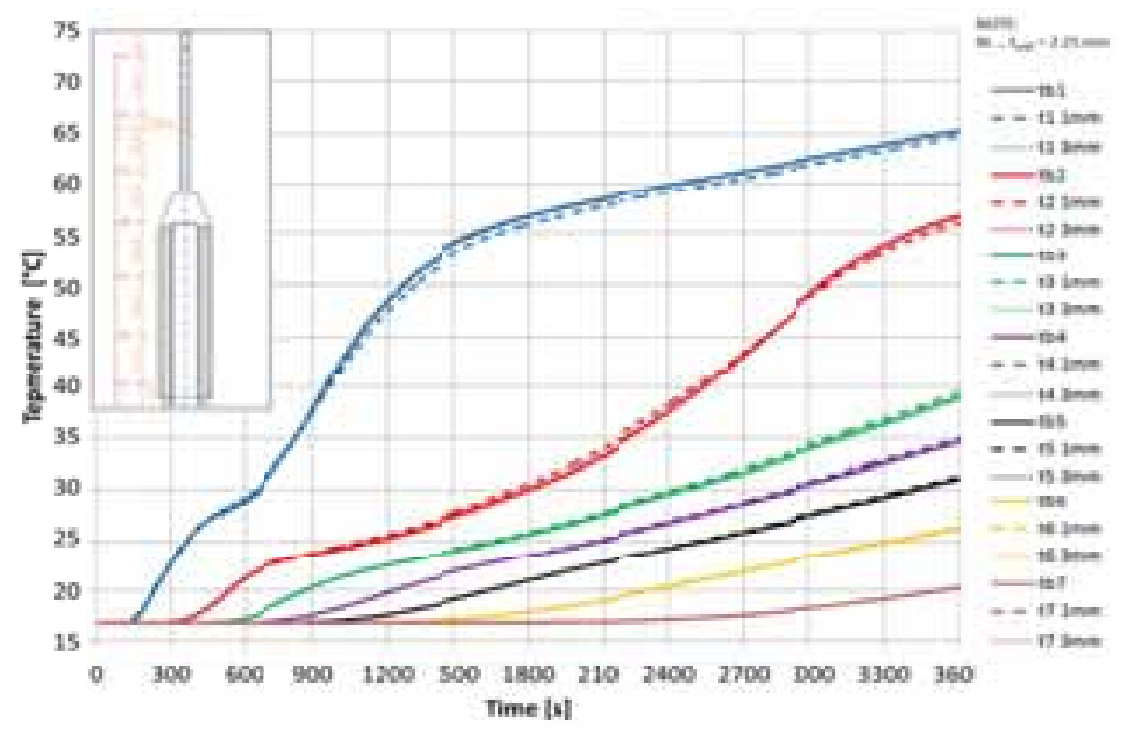

Figur 6. Calculated tank temperatures during a 1 (h) charge for different PEX pipe wall thicknesses.

\subsection{Opening area at the top of the PEX pipe}

Water heated by the heating element will rise up and enter into the PEX pipe. At the top of the PEX pipe, there are holes in the pipe that allow heated water enter into the tank. With an increase of the number of holes, the opening area increases. Fig. 7 shows calculated water temperatures after 1 (h)s of charging with different opening areas at the top of the PEX pipe. The reference number is 12 holes, represented by 'tb*', where * represents an integral number from 1 to 7 . ' $t * 6$ ' and ' $t$ * 24 ' show the result for 6 holes and 24 holes respectively. It is shown that thermal stratification in the tank is not influenced by varying the number of holes from 6 to 24 .

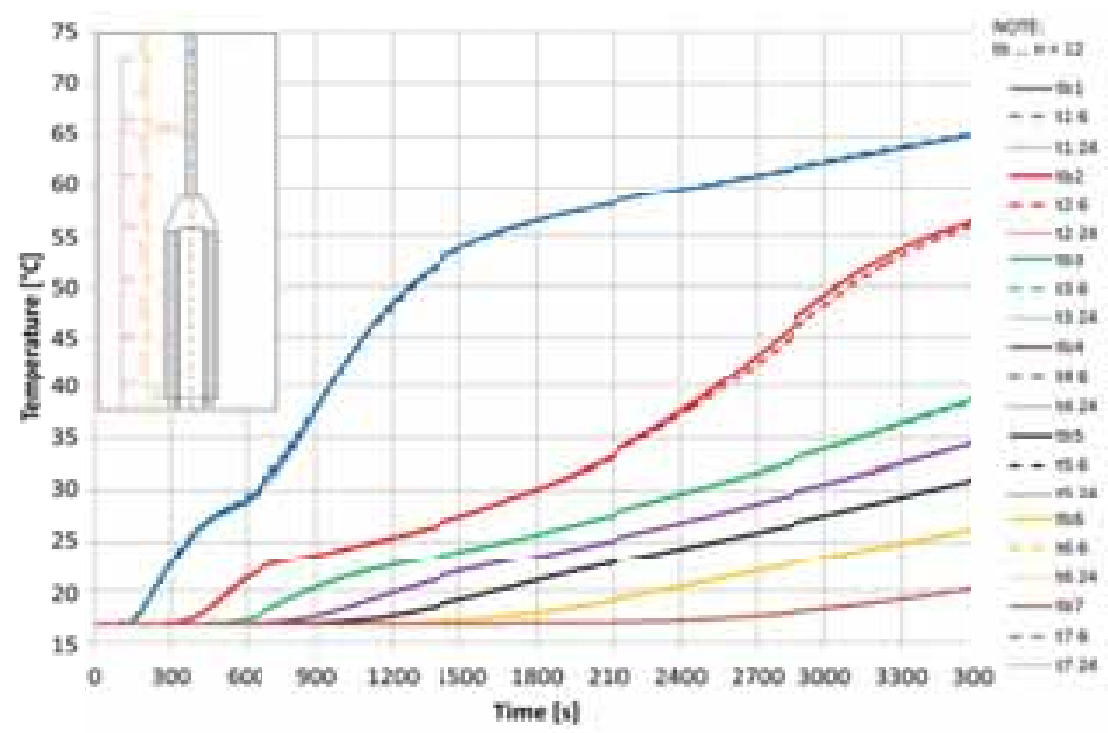

Figur 7. Calculated tank temperatures during a 1 (h) charge for different opening areas at the top of the PEX pipe.

\subsection{Opening area between the steel pipe and the PEX pipe}

In between the conic top of the steel pipe and the PEX pipe, there is a hole with smaller diameter than both the steel pipe and the PEX pipe. In the experiment, the opening area is $21.3 \%$ of the PEX cross section area. Investigations were carried out to study the influence of diameter of the opening area on calculated temperatures. The following opening areas were calculated: $5 \%, 10 \%, 15 \%, 30 \%$ and $40 \%$ of the PEX cross section area. The results of the calculation with different opening areas are shown in Fig. 14, 15 and 16. It 
can be seen that the opening area influences significantly water temperatures in the tank. After 1 hour of charging the water temperature at the top of the tank is the highest for the tank with an opening area of $10 \%$ in between the steel pipe and the PEX pipe.

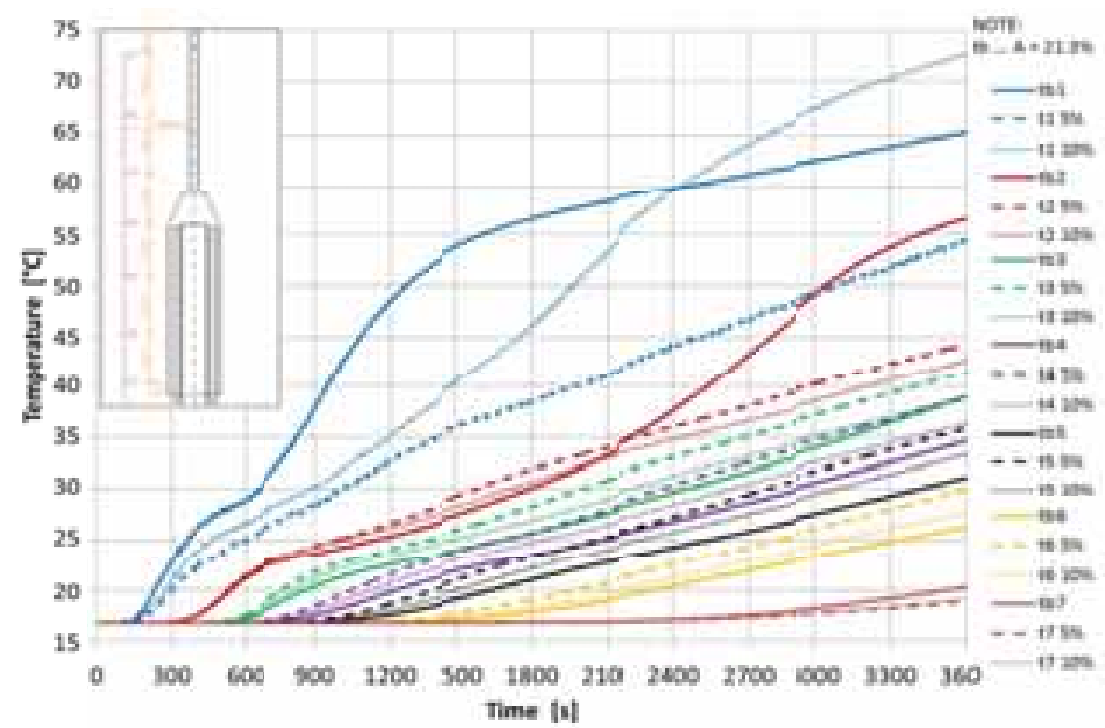

Figur 8. Calculated tank temperatures during a $1 \mathrm{~h}$ charge for different opening areas between the conic steel pipe and the PEX pipe.

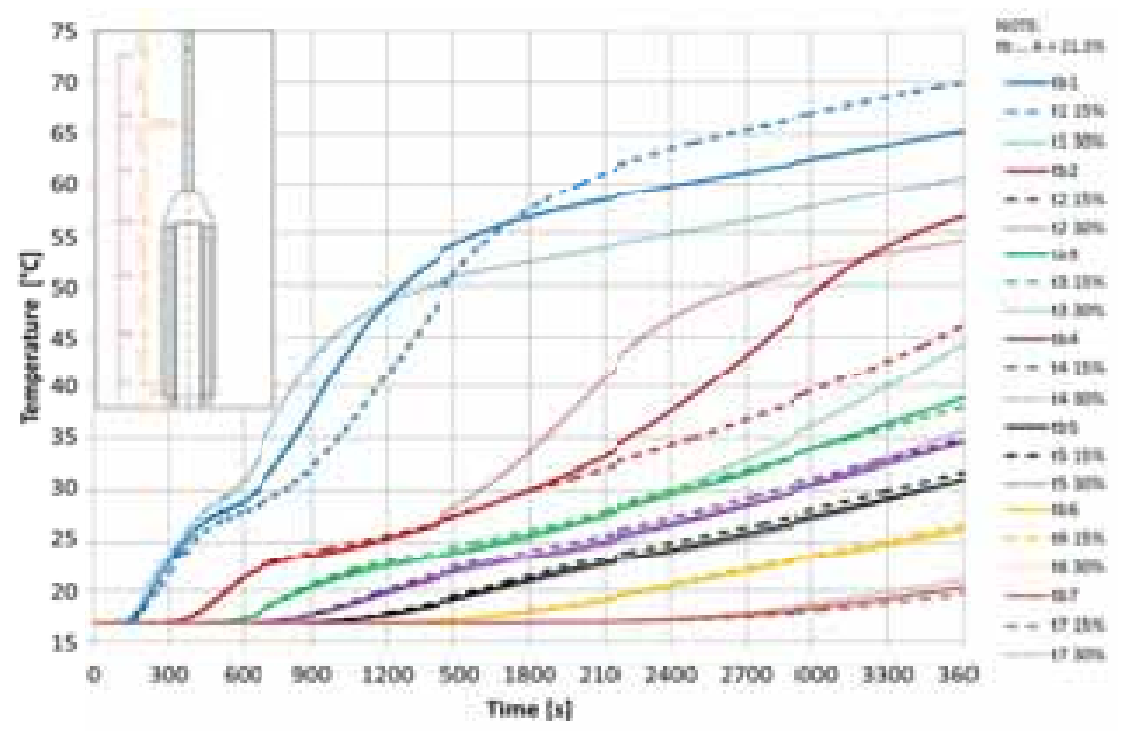

Figur 9. Calculated tank temperatures during a 1 (h) of charge for different opening areas between the conic steel pipe and the PEX pipe.

The reason of the best thermal stratification for an opening area of $10 \%$ could be explained by the buoyancy driven flow due to charging. For a slower movement of the buoyancy driven flow, water will have adequate time to be heated to a higher temperature. On the other hand, if the flow is too slow, heat will be lost from the heated water to water in the tank through the pipe walls. Therefore a decrease of the opening area from $10 \%$ to $5 \%$ will result in a lower water temperature at the top of the tank, see Fig. 8 , while with an increase of the opening area from $10 \%$ to $15 \%$ or larger, the buoyancy driven flow in the pipe will be increased therefore resulting in a lower water temperature at the top of the tank. 


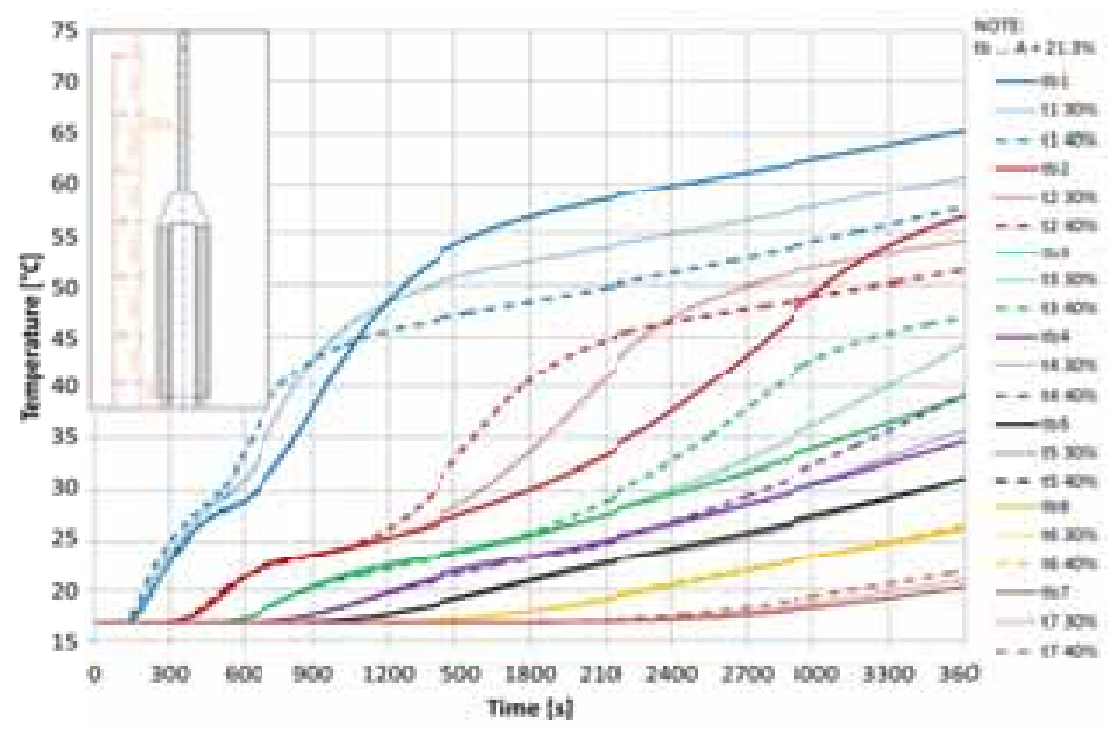

Figur 10. Calculated tank temperatures during a 1 (h) of charge for different opening areas between the conic steel pipe and the PEX pipe.

Fig. 11 shows calculated effective energy content of the tank for different opening areas between the conic steel pipe and the PEX pipe. The effective energy of the tank is obtained by summing up energy content of water in the tank with a temperature higher than $50^{\circ} \mathrm{C}$. Therefore it determines the useful energy of the tank after charging. It shows that the opening area has a significant influence on the effective energy content of the tank. Charging of a tank with an opening area in between $21.3 \%$ and $30 \%$ of the cross section area of the PEX pipe will result in the largest effective energy content. It means that although an opening area of $10 \%$ will result in the highest water temperature in the tank but the effectively energy content of the tank is not the largest because the relative slower fluid flow in the pipe means smaller water volume heated to $50^{\circ} \mathrm{C}$ at the end of charging.

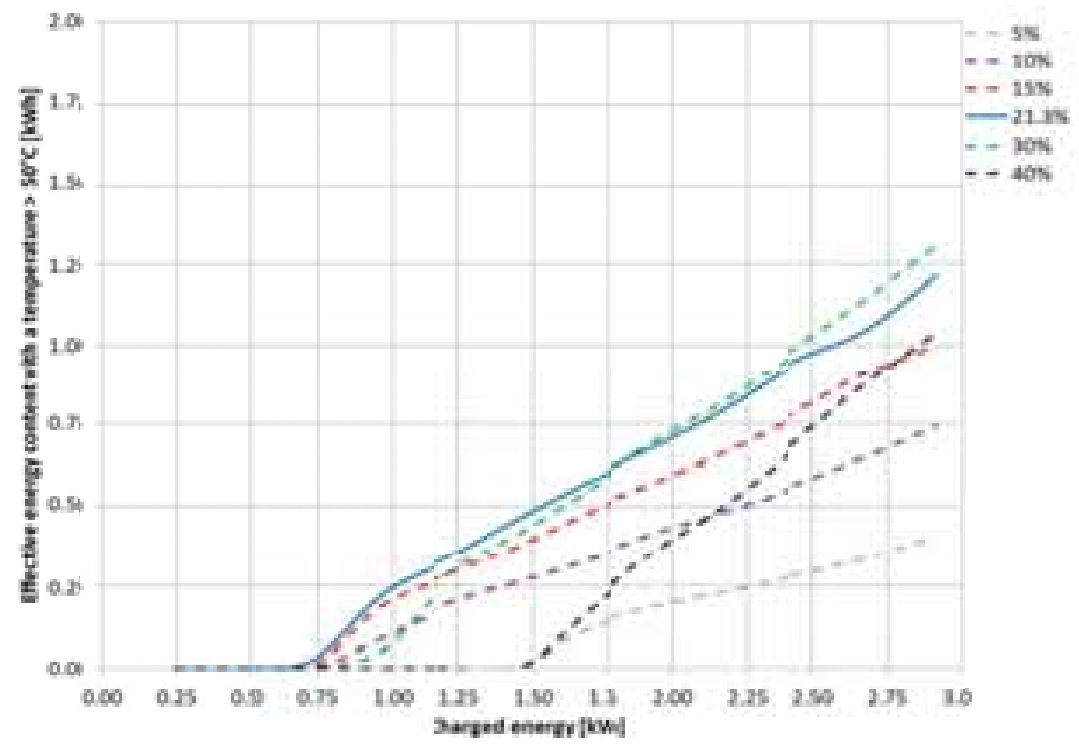

Figur 11. Calculated effective energy content of the tank for different opening areas between the conic steel pipe and the PEX pipe.

\subsection{Diameter and wall thickness of the steel pipe}

Fig. 12 shows calculated water temperatures in the tank for different diameters of the steel pipe. In the experiment the steel pipe has a diameter of $114.9 \mathrm{~mm}$ and a wall thickness of $4.25 \mathrm{~mm}$, therefore it is used as reference. A diameter of $110 \mathrm{~mm}$ and $125 \mathrm{~mm}$ are used in the investigations. It can be seen in Fig. 12 that 
the diameter of the steel pipe has insignificant influence on water temperature in the tank after 1 hour of charging.

Calculations were carried out for a wall thickness of $1 \mathrm{~mm}$ and $2 \mathrm{~mm}$. The results show that there is almost no difference in temperatures with a decrease of wall thickness from $4.25 \mathrm{~mm}$ to $1 \mathrm{~mm}$ and $2 \mathrm{~mm}$.

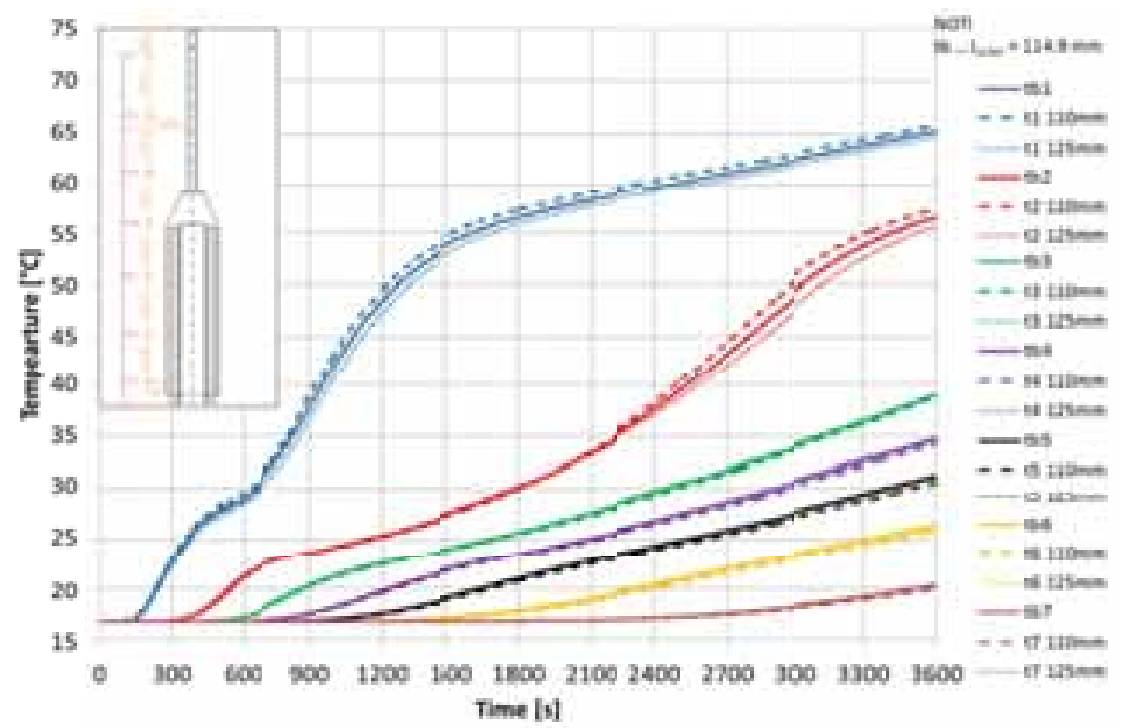

Figur 12. Calculated tank temperatures during a 1 (h) of charge for different diameters of the steel pipe.

\subsection{Different materials of the pipe around the heating element}

In the experiment the pipe around the heating element is made of steel. Investigations were carried out to study the influence of material of the pipe on water temperature in the tank. In addition to steel as a reference, PEX and PP are used as pipe materials. The results are shown in Fig. 13. It can be seen that pipe material has a strong influence on water temperature in the tank. The lower the thermal conductivity of the pipe material, the better the thermal stratification in the tank is. For a pipe made of material with a higher thermal conductivity for example steel, the water temperature at the bottom part of the tank will be higher due to heating by horizontal heat transfer across the pipe. On the other hand, the lower the thermal conductivity of the pipe around the heating element, the higher the water temperature at the top of the tank will be, for example, when PP is used as pipe material.

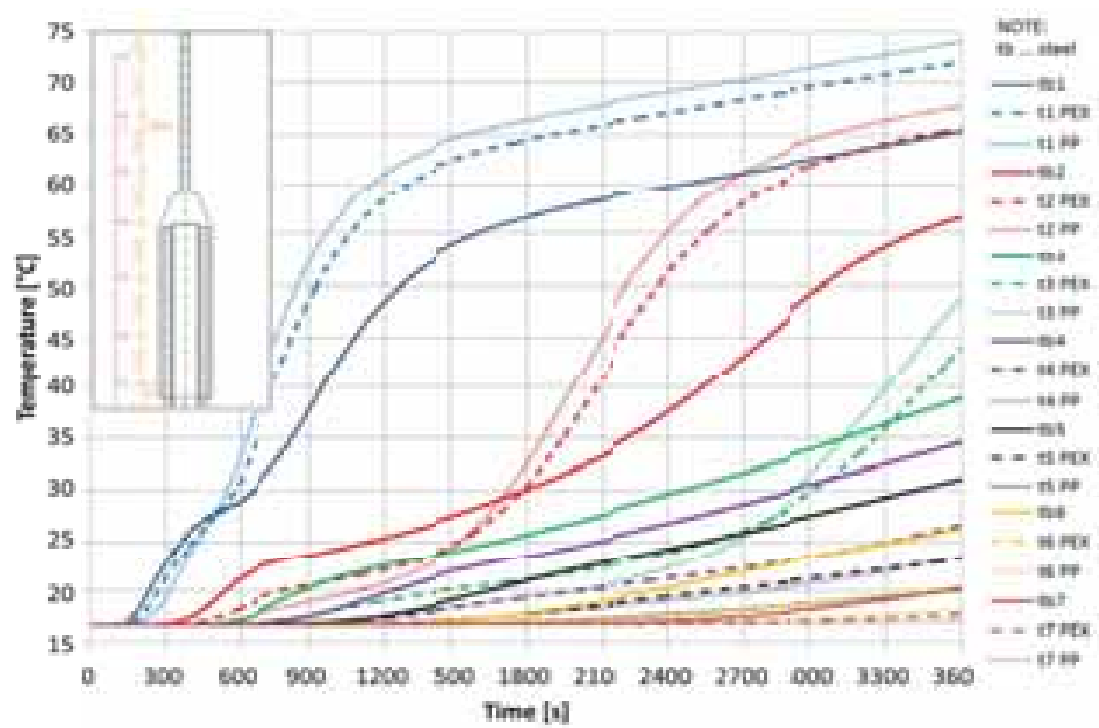

Figur 13. Calculated tank temperatures during a 1 (h) of charge for different pipe materials. 
Fig. 14 and 15 show velocity vectors around the heating element with steel and with PP as pipe material respectively. As shown in Fig. 14, there is a dominant upward flow around the heating element due to heating of water in the stratification device, while along the pipe wall there is an apparent downward flow caused by heat loss from the steel pipe wall in the horizontal direction. The uprising flow collides with the downward flow, creating flow circulations in the conic top.

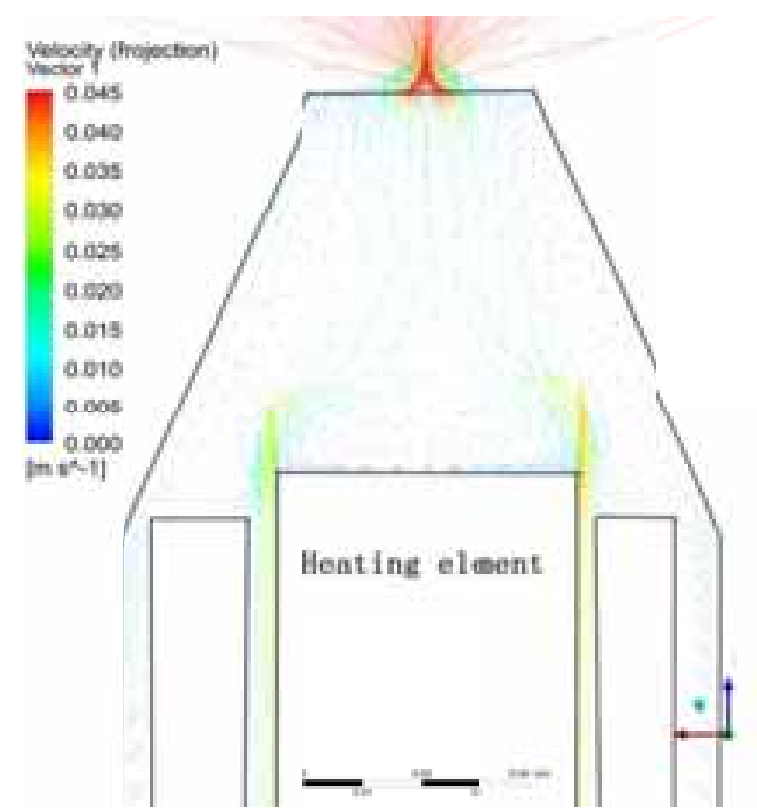

Figur 14. Velocity vectors around the heating element with steel as pipe material.

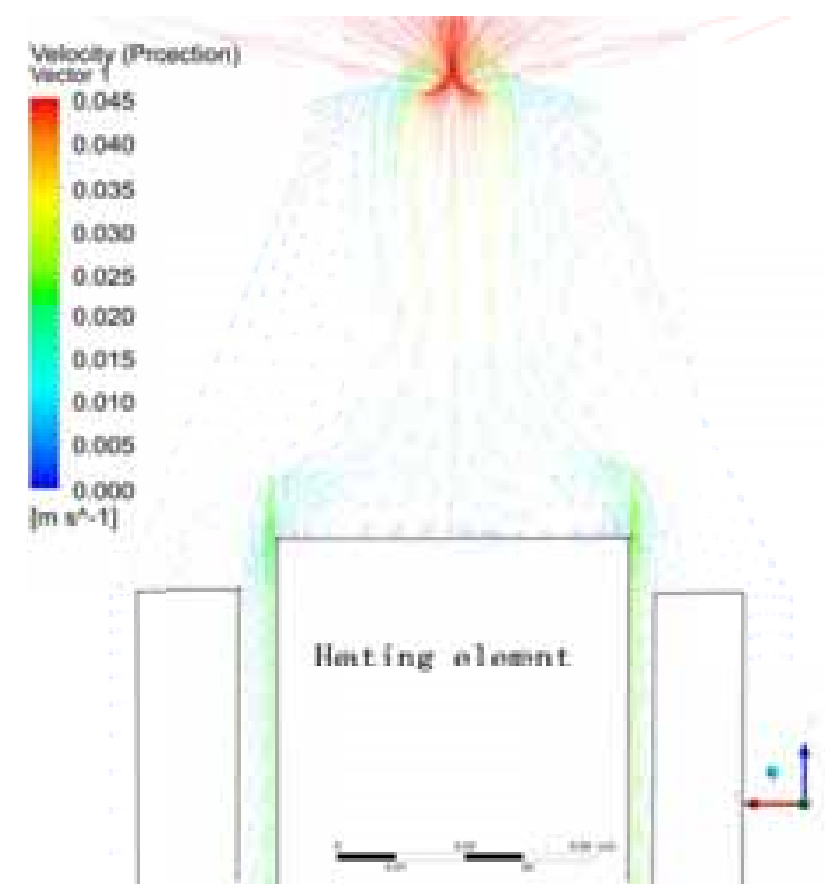

Figur 15. Velocity vectors around the heating element with PP as pipe material.

When PP is used as pipe material, the downward flow along the pipe wall is minimized, which can be explained by lower thermal conductivity of PP compared to steel. Since heat loss from the pipe is significantly reduced, the driving force of the downward flow becomes smaller. As a result water flow around and above the heating element is more regular, resulting in a higher water temperature when it enters the plastic pipe. Therefore it can be concluded that use of a material with lower thermal conductivity for the pipe around the heating element has the following advantages: 
(1) increased temperature at the top of the tank

(2) decreased heat transfer between the stratification device and the bottom of the tank

(3) better thermal stratification in the tank and thus higher effective energy content of the tank after charging.

\section{Conclusions}

A newly developed thermal stratification device was investigated by means of experiments and computational fluid dynamics (CFD) simulations. Experiments have been carried out to measure water temperatures at different levels of the tank during charging by a vertical heating element integrated in the stratification device. Transient fluid flow and heat transfer in the tank during charging are calculated by a simplified CFD model. The CFD calculated water temperatures are compared to the measured temperatures. The results show that the CFD model can satisfactory predict thermal stratification in the tank during charging.

A parametric study has been carried out to investigate how thermal stratification in the tank is influenced by design of the stratifier such as pipe thickness, material type, diameter of the pipe, opening area etc. The investigations elucidate how well a hot water tank heated at the bottom with a vertical heating element can be stratified by using the new stratifier design. The results show that diameter and wall thickness of the PEX pipe have minor influence on thermal stratification in the tank if the diameter of the pipe is in the range of 16-25 mm and the wall thickness is in the range of 1-3 mm. Opening area at the top of the PEX pipe has insignificant influence on water temperature in the tank during charging while opening area in between the PEX pipe and the conic pipe has a significant influence. The calculations show that an opening area of $10 \%$ of the cross section area of the PEX pipe gives the highest water temperature at the top of the tank but the effective energy content of the tank is the largest if an opening area in between $21.3 \%$ and $30 \%$ is used.

Concerning the pipe around the heating element, diameter and wall thickness has almost no influence on water temperature in the tank if steel is used as pipe material. Use of a material with lower thermal conductivity for the pipe around the heating element will result in a higher temperature at the top of the tank and an increased degree of thermal stratification in the tank.

\section{Acknowledgements}

This research was supported by the Danish ELFORSK Research Program and by the Special fund for the development of small and medium enterprises (EU China Cooperation Program) SQ2013Z0G100002.

\section{References}

Andersen E, Furbo S, Theoretical comparison of solar water/space heating combi systems and stratification design options. Journal of Solar Energy Engineering 2007; 129: 438-448.

Fan J, Furbo S. Buoyancy driven flow in a hot water tank due to standby heat loss. Solar Energy 2012; 86:3438-3449.

Fan J, Furbo S. Thermal stratification in a hot water tank established by heat loss from the tank. Solar Energy 2012; 86:3460-3469.

Furbo S. Varmelagring til solvarmeanlæge, PhD report, No. 162, Thermal Insulation Laboratory, Technical University of Denmark, 1984.

Furbo S, Mikkelsen S. Is low flow operation an advantage for solar heating systems? Proceedings of the ISES Solar World Congress Hamburg, Germany, Bloss, W. H. and Pfisterer, F., Pergamon Press, Oxford, 1987;962-966.

Furbo S, Knudsen S. Improved design of mantle tanks for small low flow SDHW systems. International Journal of Energy Research 2006; 30: 955-965.

Hollands K, Lightstone M. A review of low-flow stratified-tank solar water heating system. Solar Energy 1989;43: 97-105.

van Koppen C, Thomas J, Veltkamp W. The actual benefits of thermally stratified storage in a small and medium size solar systems. Proceedings of the ISES Solar World Congress, 1979, Atlanta, USA, 1979; 579-580. 